\title{
O CUIDAR DO DOENTE MENTAL CRÔNICO NA PERSPECTIVA DO ENFERMEIRO: UM ENFOQUE FENOMENOLÓGICO'
}

Vânia Regina Bressan ${ }^{2}$

Maria Cecilia Morais Scatena ${ }^{3}$

Bressan VR, Scatena MCM. O cuidar do doente mental crônico na perspectiva do enfermeiro: um enfoque fenomenonlógico. Rev Latino-am Enfermagem 2002 setembro-outubro; 10(5):682-9.

Este estudo se propõe, através do método fenomenológico, compreender o fenômeno: o cuidar do doente mental crônico internado na perspectiva do enfermeiro. Foram coletados os discursos de enfermeiros que trabalham com doentes mentais crônicos em dois macrohospitais do interior do Estado de São Paulo e realizada observação dos locais. Além do estudo com a finalidade de desvelar a visão que o enfermeiro tem do doente mental crônico, desvelou-se também a percepção do enfermeiro no cuidado/trabalho com tais pacientes. Uma reflexão sobre o cuidar, aproximando-se do pensamento de Heidegger, foi realizada, o que possibilitou chegar à sua compreensão.

DESCRITORES: saúde mental, cuidados de enfermagem, enfermagem psiquiátrica

\section{CARING ABOUT THE CARE PROVIDED TO THE MENTALLY ILL IN NURSES' PERSPECTIVE: A PHENOMENOLOGICAL FOCUS}

The purpose of this study, using the phenomenological framework, was to understand the phenomenon: caring about the care provided to the mentally ill patients in nurses' perspective. Therefore, authors interviewed nurses who work with mentally ill patients in two hospitals located at a city in the interior of the state of São Paulo, Brazil and also observed these places. In addition to the study with the aim of finding out nurse's view regarding the chronically ill patient, authors found out about nurse's perception about the care/work provided to these patients. Authors also reflected on caring, considering Heidegger's thought, what enabled them to better understand the phenomenon.

\section{EL CUIdAR del enfermo MENTAL CRÓNICO EN LA PERSPECTIVA DEL ENFERMERO: UN ENFOQUE FENOMENOLOGICO}

Este estudio propone, a través del método fenomenológico, a comprender el fenómeno: el cuidar del enfermo mental crónico internado desde la perspectiva del enfermero. Fueron recolectados los discursos de los enfermeros que trabajan con enfermos mentales crónicos en dos macro-hospitales del interior del Estado de São Paulo y realizada una observación en los locales. Más allá del estudio con la finalidad de desvelar la visión que el enfermero tiene del enfermo mental crónico, se desveló también la percepción del enfermero en el cuidado/trabajo con tales pacientes. Una reflexión sobre el cuidar, aproximándose al pensamiento de Heidegger, fue realizada, lo que hizo posible llegar a su comprensión.

DESCRIPTORES: salud mental, cuidados de enfermería, enfermería psiquiátrica

\footnotetext{
${ }^{1}$ Síntese da dissertação de Mestrado apresentada à Escola de Enfermagem de Ribeirão Preto da Universidade de São Paulo em junho/1998 Área de concentração: Enfermagem Psiquiátrica; ${ }^{2}$ Enfermeira, Mestre em Enfermagem Psiquiátrica, e-mail: Vania.Bressan@bigfoot.com; ${ }^{3}$ Orientador, Professor Associado da Escola de Enfermagem de Ribeirão Preto da Universidade de São Paulo, Centro Colaborador da OMS para o desenvolvimento da pesquisa em enfermagem
} 


\section{INTRODUÇÃO}

$\boldsymbol{A}$ ausência de programas de reabilitação de doentes mentais crônicos, internados em hospitais psiquiátricos do Brasil, começou a me inquietar ao habitar esse mundo, através da vivência do cuidado a tais pacientes. Percebi que a reabilitação psicossocial não era preocupação central de alguns profissionais nem mesmo da administração desses hospitais.

Através da prática, percebia os enfermeiros preocupados com questões diversas, contudo, o cuidar do doente mental crônico parecia ficar em segundo plano, como se não houvesse nada a ser feito em relação a esse tipo de paciente. Essa inquietação impulsionou-me à realização de estudo que me auxiliou a compreender melhor essa temática.

Após estudo realizado no Brasil, em 1992, estimou-se que um terço dos pacientes internados nos hospitais psiquiátricos são crônicos, residentes nesses locais, pois perderam completamente os vínculos familiar e social. Além disso, sofrem violações dos direitos humanos e de cidadania, o que reforça a necessidade da reversão desse modelo assistencial, baseado na exclusão e no isolamento ${ }^{(1)}$.

Mudanças na assistência oferecida pelos hospitais psiquiátricos têm sido instituídas pela Coordenação da Saúde Mental do Ministério da Saúde. Entre as mudanças preconizadas, inclui-se o estabelecimento de programas para os pacientes crônicos, residentes nos hospitais psiquiátricos, com o objetivo de reconquistar sua independência e reintegrá-los à sociedade.

Há profissionais de saúde mental, contudo, que duvidam que os pacientes crônicos possam responder favoravelmente às técnicas reabilitadoras e viver em sociedade com certo grau de independência.

Autores, a maioria enfermeiros ${ }^{(2-6)}$, relatam suas experiências no desenvolvimento de programas de reabilitação de doentes mentais crônicos internados e os resultados favoráveis desse trabalho, entre os quais destacam-se a independência do paciente para autocuidados, melhora da auto-estima (cuidam mais de sua aparência pessoal), melhora do relacionamento interpessoal e o mais importante - diminuição das readmissões hospitalares.

O trabalho com familiares (quando os pacientes as têm) e com segmentos da sociedade é de suma importância na reintegração do paciente à sociedade civil.
Esse trabalho, entre outros programas, é recomendado pela Portaria da Secretaria de Assistência à Saúde do Ministério da Saúde ${ }^{(7)}$, pela Organização Mundial da Saúde, desde $1964^{(8)}$.

A reabilitação psicossocial implica em ética de solidariedade que viabilize aos sujeitos com limitações para os afazeres cotidianos, decorrentes de transtornos mentais severos e persistentes, o melhor nível possível de autonomia para a vida na comunidade ${ }^{(9)}$.

Quem são, afinal, essas pessoas consideradas pela literatura ${ }^{(4,8,10)}$ como aquelas que possuem transtornos mentais severos e persistentes, ou seja, os denominados pacientes crônicos? Esses assim são considerados porque tais transtornos interferem em sua capacidade funcional sobre três ou mais aspectos primários da vida diária, como o autocuidado, autonomia, relações interpessoais, trabalho, aprendizagem, necessitando de atenção hospitalar ou tratamento psiquiátrico prolongados, os quais dificultam o desenvolvimento de sua própria auto-suficiência econômica ${ }^{(4,8,10)}$.

O doente com incapacidade mental severa deve satisfazer, no mínimo, uma das seguintes condições: apresentar uma única hospitalização nos últimos cinco anos de, ao menos, três meses de duração, ou duas ou mais durante um intervalo de doze meses ${ }^{(4,8,10)}$.

\section{OBJETIVO}

Diante do exposto, proponho-me estudar o fenômeno: "o cuidar do doente mental crônico internado na perspectiva do enfermeiro".

\section{FENOMENOLOGIA: O REFERENCIAL TEÓRICO-METODOLÓGICO}

A fenomenologia surgiu no final do século XIX com Edmund Husserl (1859-1938), na Alemanha, num contexto de crise da filosofia e da ciência pura, crise da qual ainda não saímos e que se retratou por objetivar todos os achados da ciência no chamado positivismo, levando os pensadores do psiquismo a se voltarem para a subjetividade, até então eliminada ${ }^{(11)}$.

Enquanto o positivismo estuda os fatos, constituindo-se fato tudo aquilo que pode se tornar objetivo, a fenomenologia de Husserl estuda os fenômenos, ou seja, 
tudo aquilo que se mostra e que se manifesta para uma consciência $^{(12)}$

Fenômeno refere-se a qualquer coisa que se faça presente, seja ela um ruído, um perfume, uma lembrança, qualidade ou atributo que, ao ser experienciada, passa a ser descrita por aquele que a vivenciou ${ }^{(13)}$. Então, para Husserl, o fenômeno só tem sentido em sua manifestação na vivência.

Aprendemos com a fenomenologia as qualidades das coisas, uma característica da consciência, por ser ela quem dá sentido às mesmas. Esse sentido, porém, é concebido estando a consciência correlacionada com o objeto. Assim, a consciência é sempre "consciência de alguma coisa", estando dirigida para um objeto que também é sempre "objeto para uma consciência".

Para se chegar à essência do fenômeno, ou seja, às significações vividas na existência humana concreta, Husserl fala de redução eidética, ou seja, redução do eu do pesquisador, que consiste em deixar de lado suas experiências, crenças, teorias e explicações a priori para se chegar à essência, às coisas nelas mesmas. Esse momento é chamado de epoché.

Todo fenômeno deve ser situado, ou seja, para ser compreendido, deve ter sido ou estar sendo vivenciado pelo sujeito, numa dada situação.

A entrevista, caracterizada pelo uso da linguagem (logos) entre o entrevistador e entrevistado, é um modo de acesso aos sujeitos na modalidade de pesquisa fenomenológica.

O cuidado na enfermagem em suas diferentes áreas, inclusive na psiquiátrica, vem se modificando com o passar das décadas, pois a enfermagem sentiu a necessidade de se chegar mais próximo do paciente, numa relação interpessoal mais intensa e terapêutica. Pensando assim, e tendo como objeto de trabalho o estar com o outro, um ser que se situa num contexto peculiar, a enfermagem psiquiátrica busca o sentido desse ser e começa a refletir sobre seu cuidar. Nessa perspectiva é que a enfermagem faz uso da fenomenologia.

Vários estudos fenomenológicos ${ }^{(14-16)}$ têm surgido na área da enfermagem psiquiátrica, trazendo contribuições importantes para a mesma.

\section{TRAJETÓRIA METODOLÓGICA}

Para a compreensão do cuidar do doente mental crônico internado, segundo a perspectiva do enfermeiro, primeiramente habitei e observei o mundo habitado por eles (o hospital psiquiátrico) e, posteriormente, coletei o discurso de enfermeiros que trabalham em unidades hospitalares de pacientes crônicos em macrohospitais psiquiátricos, tendo como questão norteadora: como é para você trabalhar com doentes mentais crônicos internados?

Primeiramente solicitei à direção dos 2 hospitais psiquiátricos, escolhidos para o desenvolvimento deste estudo, autorização para a realização da pesquisa. Fui autorizada por ambas. O projeto de pesquisa não foi submetido à análise do Comitê de Ética em Pesquisa, já que as mesmas não o possuíam, uma vez que os Comitês de Ética em Pesquisa foram instituídos após a Resolução 196/96 do Conselho Nacional de Saúde, de outubro de $1996^{(17)}$. Portanto, a autorização às instituições foi solicitada antes dessa resolução.

Após explicar aos enfermeiros a finalidade da entrevista, assegurando-Ihes o anonimato dos depoimentos, fui autorizada por eles a realizar a entrevista. Essa autorização foi feita verbalmente, sem a assinatura de qualquer impresso que caracterizasse um consentimento informado, devido à resolução do Conselho Nacional de Saúde, no que se refere ao termo de consentimento livre e esclarecido não estar em vigor ainda, na época da coleta dos dados.

Após ser autorizada, permaneci uma semana em cada instituição, nos períodos da manhã e tarde, para realizar o pretendido. A coleta dos dados deu-se em dezembro/1996 e janeiro/1997.

A escolha de dois hospitais psiquiátricos para coleta dos dados deu-se devido às diversidades apresentadas por ambos, desde a estrutura física até a terapêutica adotada. Dessas diversidades, emergiram e foram apreendidas as facetas do fenômeno cuidar de doentes mentais crônicos, possibilitando chegar à sua estrutura geral.

Esses hospitais estão localizados no interior do Estado de São Paulo. Chamei-os de hospital A e hospital $B$, respeitando os preceitos éticos que envolvem 0 desenvolvimento da pesquisa. Ambos são instituições espíritas conveniadas com o SUS (Sistema Único de Saúde), sendo que o hospital B possui unidades particulares de assistência psiquiátrica.

O cuidado em enfermagem é considerado, por alguns autores ${ }^{(18-20)}$, como a assistência direta aos 
pacientes. Desse modo, em meus encontros com os enfermeiros, optei pela utilização do termo trabalho: como é para você trabalhar com doentes mentais crônicos internados?

Penso que o termo trabalhar é mais abrangente, pois envolve todas as atividades desenvolvidas pelo enfermeiro visando o bem-estar do paciente, sejam elas de supervisão, organização, planejamento e execução de programas assistenciais, educação continuada em enfermagem, liderança, tomada de decisão e assistência ao paciente ${ }^{(21)}$.

Foram coletados 16 depoimentos de enfermeiros: 9 do hospital A e 7 do hospital B. Após a coleta dos discursos, foi efetuada a análise dos mesmos ${ }^{(12)}$, constituindo-se de 4 momentos:

- leitura atenta dos depoimentos sem buscar ainda qualquer interpretação ou identificar qualquer atributo ou elemento, a fim de chegar ao sentido geral do que está descrito;

- quando um sentido foi obtido, o pesquisador volta ao início e lê novamente o texto, tentando apreender significados na descrição, dentro de uma perspectiva (de enfermeira que sou), focalizando o fenômeno que está sendo pesquisado;

- ao apreender os significados, o pesquisador obtém unidades de significação;

- o pesquisador realiza a convergência das unidades de significação de todas as descrições para chegar a categorias temáticas, realizando, assim, análise da estrutura do fenômeno.

Foi realizada a análise da estrutura do fenômeno situado e se chegou à compreensão do fenômeno cuidar de doentes mentais crônicos, na perspectiva daquele que vivencia o cuidado, o enfermeiro.

\section{RESULTADOS E DISCUSSÃO}

A estrutura geral do fenômeno

Sob a perspectiva do enfermeiro, pude apreender facetas do fenômeno cuidar de doente mental crônico internado que revelam a estrutura do fenômeno estudado, que nos mostra aspectos que compõem o cuidar, bem como a visão dos enfermeiros acerca do doente mental.

O cuidar, na perspectiva do enfermeiro, compreende 3 momentos:
1) o antes de entrar em contato com a pessoa a ser cuidada:

O primeiro contato com o doente mental crônico causa medo

Pedro: ... na hora que eu me deparei com aquilo fiquei assustado...*

2) após familiarizar-se com a pessoa cuidada:

Depois do primeiro contato com o doente mental crônico, o enfermeiro se acomoda, se acostuma e sabe o que esperar do paciente

Pedro: ... fiquei assustado, mas no fim me acostumei com eles...

3) o acontecer do cuidado através do seu cotidiano:

Trabalhar com doente mental crônico é difícil, porém gratificante

Fabiana: ... apesar de não ser um serviço muito fácil, ... porque os crônicos eles exigem mais da gente: mais tempo, mais disposição, ... é mais gratificante, mais gostoso.

O enfermeiro sente-se valorizado trabalhando com doente mental crônico

Luciana: ...também porque eu chego eles já me solicitam...é um sinal que eles gostam eu tô contente de mim, né e eles querem tá junto.

O trabalho com doente mental crônico compreende atividades assistenciais e de supervisão

Vera: ... eu acho que em primeiro lugar, trabalhar com doente mental exige paciência, muita dedicação, ... dar carinho, dar amor, ouvir, ... incentivar, estimular...

O cuidar apresenta limitações oferecidas pela administração hospitalar e pela equipe multidisciplinar

Roberto: ... você não pode ser criativo, você tem que seguir somente aquilo que eles dita..

Ao relacionar-se, no cuidar, o enfermeiro passa a conhecer o doente mental crônico. Conhecendo-o, pode descrevê-lo, como:

Paciente morador, abandonado pela família

Sandra: ...era mais por incontinência da família também, por não entender. Eles deixam, abandonam mesmo o filho aqui. ...não tem assistência nenhuma da família...é uma não aceitação mesmo.

Amigo, parte da família, outra pessoa "normal"

Mirela: ...eu vejo como pessoas normais, até certo ponto, porque eu me relaciono bem com todos eles...uma função maternal, sabe. ...uma conversa amigável...

Carente, dependente em relação à enfermagem, incapaz de pensar

\footnotetext{
* Unidades significativas originárias dos depoimentos dos enfermeiros, cujos nomes são fictícios, preservando a identidade dos mesmos
} 
Silvana: ... eles são carentes, são umas crianças que precisam de tudo.

Diferente de pacientes alcoolistas e drogaditos

Pedro: ... eu não consigo trabalhar muito com alcoólatras,

não tenho aquele relacionamento tão bom como com eles.

Um ser com possibilidades

Nelson: ... porque... você trabalhando com esse doente, ...você consegue reverter esse quadro dele...

Ao familiarizar-se com o doente mental crônico, o enfermeiro, antes com medo, passa a acostumar-se com ele, saber o que dele esperar, pois é um paciente morador e abandonado pela família, o que leva à não rotatividade da clientela, contribuindo para a construção de um vínculo afetivo com o enfermeiro. Esse passa a considerá-lo um amigo, membro da família, uma pessoa com características normais.

Essa pessoa é carente, contudo, dependente em relação à enfermagem e incapaz de pensar sozinho, o que faz a enfermagem assumir um papel maternal, estabelecendo com o paciente uma relação mãe-filho, relembrando e reforçando a dependência dos doentes na relação do cuidado ${ }^{(22)}$.

Os doentes mentais crônicos são os filhos afetuosos e por isso o enfermeiro sente-se valorizado ao trabalhar com esse paciente.

O cuidar assume características assistenciais: cuidados com a higiene, aparência pessoal, orientar, estimular, ouvir, tocar o paciente, realizar trabalho com familiares - e de supervisão: controlar a equipe de enfermagem e integrar a equipe multidisciplinar.

Alguns dos enfermeiros que trabalham no hospital A e outros que trabalham no hospital B vêem o doente mental crônico como um ser com possibilidades de melhora. Daqueles que acreditam no doente mental crônico, porém, somente alguns trabalham com a sua reabilitação, desenvolvendo atividades como: grupo de reeducação alimentar, grupo de orientação a autocuidados, entre outras.

Os que mais realizam esse trabalho encontramse no hospital $\mathbf{B}$, pois nesse local têm mais autonomia e participação no processo terapêutico do paciente.

Embora o enfermeiro do hospital $\mathbf{B}$ tenha mais autonomia, seja mais participante da equipe multiprofissional e realize algumas atividades de ressocialização com o interno crônico, o fazer dos enfermeiros do hospital A e B não vai além da instituição, ou seja, seu fazer se dá somente dentro da instituição, não atinge segmentos da sociedade e nem as famílias dos internos.

Além disso, a instituição não oferece outra possibilidade de tratamento senão a forma custodial, na qual oferece abrigo, comida, medicação e agasalho. Não trabalha para que o doente mental crônico retome sua autonomia, segundo suas potencialidades e possibilidades, não oferece um hospital-dia, um centro de apoio psicossocial, um lar abrigado, uma pensão protegida.

Essa situação contribui cada vez mais para a exclusão do indivíduo da sociedade, reforça a submissão do interno, sua postura estereotipada, a ausência de perspectiva de um futuro melhor e da melhora de seu quadro psicopatológico, ou seja, contribui e reforça a situação de cronicidade do doente mental.

O que se mostra é que o cuidar não depende só da relação enfermeiro-paciente, mas também da relação enfermeiro-paciente-administração hospitalar-equipe multidisciplinar. Desse modo, o cuidado do enfermeiro ao doente mental crônico, especificamente daqueles que trabalham no hospital A, é limitado, ou seja, não se dá numa descoberta de possibilidades apresentadas e exploradas pelo e no cotidiano.

O cuidar do doente mental crônico é um trabalho difícil devido às peculiaridades apresentadas pelo próprio crônico, pela instituição e equipe multiprofissional, mas é um trabalho também gratificante, porque o retorno, a valorização, a importância ao cuidado é dada pelo paciente, que recompensa o enfermeiro com afeto, com a percepção e solicitação de sua presença junto dele, dandoIhe suporte para enfrentar o mundo do hospital psiquiátrico.

Ao enfermeiro resta sentir-se valorizado pelo paciente, que lhe dá apoio para continuar na caminhada, e desvalorizado pela administração hospitalar e equipe multiprofissional, que o trata como ninguém, despersonaliza-o, massifica, apropria-se dele, assim como do paciente, retirando sua responsabilidade pelo cuidar, que passa a ser dos outros, da gente, de todos os outros, de ninguém ${ }^{(23)}$.

Compreendendo o cuidar do enfermeiro para com o doente mental crônico - uma aproximação ao pensamento de Heidegger

Na convivência com o doente mental crônico, alguns enfermeiros passam a acreditar nas possibilidades de melhorar a condição do interno que apresenta um 
quadro psicopatológico sem significativas mudanças. Esses enfermeiros apresentam atitude de solicitude ou de cuidado ${ }^{(23)}$. Para ele, a solicitude, ou seja, o relacionarse com o outro numa maneira envolvente e significante, deve conter as características básicas de consideração e paciência para com o outro. Considera-se alguém em vista de tudo o que foi vivenciado e experienciado por ele. $\mathrm{O}$ ter paciência pressupõe expectativa de algo que possa vir a acontecer.

Desse modo, a aceitação do outro em seu serno-mundo e a crença no seu vir-a-ser é uma atitude de solicitude ou de cuidado autêntico do enfermeiro para com o doente mental crônico. O cuidado autêntico está voltado para a existência do outro e não para um "o que", um objeto qualquer que é cuidado ${ }^{(23)}$. É um cuidar que deve ser intermediado pelo interesse para com o outro, possibilitando-Ihe assumir seus próprios caminhos, crescer, amadurecer, encontrar-se consigo mesmo.

Outros enfermeiros não acreditam nas possibilidades de melhora do doente mental crônico ou, se acreditam, centralizam seu cuidar no modo-de-ser da instituição e não no indivíduo enquanto Ser a ser cuidado. Esses desenvolvem um cuidar limitado, inautêntico.

O cuidar inautêntico, segundo o referencial de Heidegger, trata-se de um cuidado no qual o cuidador, ou seja, o enfermeiro, faz tudo pelo outro, domina-o, manipulao ainda que de forma sutil. Esse cuidar não auxilia o outro a vislumbrar possibilidades de vir-a-ser melhor, de se autocuidar, de pensar, agir, escolher, enfim, de ajudá-lo a encontrar o verdadeiro sentido de ser. Essa maneira de cuidar causa dependência do cliente em relação ao cuidador, pois o cuidador não deixa o paciente assumir seu próprio cuidado. Assim, indiferença, apatia e falta de interesse em relação ao outro são maneiras deficientes de solicitude ou de cuidado ${ }^{(23)}$.

O fato de os enfermeiros do hospital A apresentarem um cuidar limitado, não se sentindo parte da equipe de trabalho e não responsáveis pelo paciente, mostra o modo básico do viver com os outros, no cotidiano, o que é chamado "a gente", "todos"(23-24). A sociedade é estruturada e dirigida por organizações ou instituições onde o indivíduo fica disperso, sente-se protegido, acomodado. É empurrado à uniformidade e à mediocridade. Ninguém é mais responsável por nada. Sendo assim, o todos passa a ser ninguém ${ }^{(23)}$.

O fato de que o enfermeiro do hospital A percebese desvalorizado, não se sentindo parte da equipe e, portanto, não responsável pelo paciente, analisando sob a ótica de Heidegger, fundamenta seu cuidar na inautenticidade, embora alguns enfermeiros mostrem atitudes de um cuidar autêntico, reveladas pela paciência e pela crença de que o doente mental crônico é um ser com possibilidades. Contudo, os enfermeiros desse hospital não assumem um cuidar autêntico, centralizado na pessoa, no Ser a ser cuidado e, sim, centralizam seu cuidar no modo-de-ser da instituição que, por sua vez, não se responsabiliza por oferecer uma estrutura adequada para que o cuidado aconteça, dominando os enfermeiros e pacientes, massificando-os, fazendo-os submissos, propriedade sua. Enfermeiro e paciente, então, perdem o livre-arbítrio, o poder de decidir, de opinar, de agir, não vislumbrando horizontes de possibilidades.

A responsabilidade pela reabilitação do paciente do hospital $\mathbf{A}$, que deveria ser de todos, torna-se de ninguém.

Essa é uma situação que deve ser revertida através da modificação do modo-de-ser com o outro, passando do cuidar inautêntico ao autêntico, permitindo que haja crescimento e reencontro com o próprio modo-de-ser autêntico do ser enfermeiro e doente mental crônico, possibilitando o dar-se das existências, das potencialidades e dos desejos de um mundo melhor.

Para que haja um cuidado autêntico por parte do enfermeiro, não é necessário que esse modifique a estrutura social da instituição, mas atue de forma humanitária ${ }^{(2)}$. Acredito que para atuar de maneira humanitária é necessário que haja proximidade e conhecimento do próprio eu do enfermeiro, antes de uma proximidade com o outro, ou seja, o cuidar autêntico se dá quando o enfermeiro percebe o doente mental como alguém que existe em seu modo peculiar de existência, a partir da percepção de si mesmo enquanto ser cuidador e agente transformador da realidade.

\section{ALGUMAS CONSIDERAÇÕES SOBRE O CUIDAR DO ENFERMEIRO PARA COM O DOENTE MENTAL CRÔNICO}

Este estudo me fez compreender que o enfermeiro, o próprio paciente, a instituição hospitalar e a equipe multiprofissional não vêem possibilidades de saída do cliente crônico do ambiente hospitalar, visto que esse é um paciente morador, que perdeu os vínculos familiar e 
social. Os familiares estão começando agora, em ritmo muito lento, a receber informações sobre o estado de doença no qual se encontra seu membro familiar, a receber auxílio e apoio para poderem acolher esse paciente novamente no seio familiar.

Um trabalho de orientação aos segmentos da sociedade também não tem sido realizado pelos profissionais de saúde mental, inclusive pelos enfermeiros, objetivando a recepção dos doentes mentais crônicos pela sociedade civil com respeito e dignidade, oferecendo-lhes apoio e emprego, o que ajudaria a diminuir o tempo e o número das reinternações.

A criação de hospitais-dia, CAPS e NAPS (Centros e Núcleos de Apoio Psicossocial), pensões protegidas e lares abrigados para os crônicos moradores dos hospitais A e $\mathbf{B}$, aqui abordados, encontra-se em discussão nessas instituições, porém nada de concreto me foi apresentado na ocasião da observação da estrutura física e projeto terapêutico de ambos os hospitais, o que contribui, de certa forma, para a permanência de uma assistência custodial e não libertadora que levaria o paciente a ser sujeito do seu cuidar, de sua própria história.

A reabilitação do doente mental crônico realizada pelo enfermeiro e o seu fazer no hospital psiquiátrico mostrou-se, neste estudo, como um trabalho de descoberta das possibilidades e potencialidades do Ser cuidado. Não como um trabalho/cuidar pronto, padronizado que se encaixa diretamente na patologia apresentada pelo cliente, conforme preconiza o modelo biomédico de assistência, adotado pela enfermagem, mas um cuidar que vai se dando no cotidiano.

Para realizar este tipo de trabalho, contudo, é necessário que o enfermeiro acredite primeiro nas suas potencialidades enquanto profissional e nas potencialidades do Ser a ser cuidado. O que se revelou neste estudo foi que a crença nas potencialidades do Ser cuidado e o cuidar sofrem interferência da administração

\section{REFERÊNCIAS BIBLIOGRÁFICAS}

1. Alves DSN, Seidl EF, Schechtman A, Correia e Silva R. Reestruturação da atenção em saúde mental: situação atual, diretrizes e estratégias. In: Amarante $\mathrm{P}$, organizador. Psiquiatria social e reforma psiquiátrica. Rio de Janeiro (RJ): FIOCRUZ; 1994. p. 195-201.

2. Goulart MCS. O enfermeiro como elemento de reabilitação do doente mental crônico hospitalizado. [dissertação]. Ribeirão Preto (SP): Escola de Enfermagem de Ribeirão Preto/ USP; 1982. hospitalar e da equipe multidisciplinar.

O conhecimento e a competência técnica dos enfermeiros não são suficientes quando estão sujeitas à submissão e obediência a quem exerce o poder e a uma atuação rígida e autoritária, essencialmente disciplinar, aprendidas na formação acadêmica e exigidas pela instituição de trabalho ${ }^{(25)}$.

As escolas de enfermagem não passam aos alunos que nas instituições de trabalho, a atuação, muitas vezes, não é centrada no cliente, mas na instituição e também não ensinam como lidar com essa situação.

Para a reversão desse quadro torna-se necessário que o ensino estimule o pensamento crítico do aluno, levando-o a ser um agente "politizador" e não um ser submisso à instituição e um agente "patologizador" de pacientes $^{(6)}$.

A abordagem fenomenológica de ensino e a utilização da Filosofia, enquanto disciplina integrante dos currículos de enfermagem, vêm auxiliar a enfermagem a compreender sua essência, que se constitui primordialmente pela relação enfermeiro-paciente que se dá através do cuidar.

Outro fator a ser considerado nesta reflexão sobre o cuidar do enfermeiro para com o doente mental crônico é que o enfermeiro parece ser o profissional que mais conhece as reações e comportamentos do cliente, pois permanece mais tempo próximo desse, podendo esse permanecer próximo conter vários significados. A proximidade do paciente enquanto relação mãe-filho, como a revelada neste estudo, não favorece o cuidar autêntico, mas reafirma a condição de dependência do doente em relação ao Ser cuidador.

A proximidade do enfermeiro do cliente, num cuidar autêntico, favoreceria a independência desse em relação ao primeiro, propiciando seu crescimento, amadurecimento, estimulando seu pensamento crítico, suas ações e relações com o meio.

3. Wong SE, Flanagan SG, Kuehnel TG, Liberman RP, Hunnicut $\mathrm{R}$, Adams - Badgett J. Training chronic mental patients to independently practice personal gromming skills. Hosp Community Psychiatry 1988 Aug; 39(8):874-8.

4. Liberman RP. Rehabilitación integral del enfermo mental crónico. Barcelona: Ed. Martinez Roca; 1993.

5. Hasitavej ML. The impact of psychoterapy and self-healing techniques when coping with chronic illness: a case study. Home Healthcare Nurse 1995; 13(6):40-3.

6. Hall BA. The psychiatric model: a critical analysis of this undermining effects on nursing in chronic mental illness. Adv Nurs Sci 1996 March; 18(3):16-26. 
7. Portaria n $^{\circ} 149$ de 7 de dezembro de 1995. Reestruturação da assistência psiquiátrica no país 199511 dez; seção 1: anexo 1, parte 2 .

8. Sgambati ERV. Reinternação e rejeição familiar: um estudo com pacientes psiquiátricos. [dissertação]. Ribeirão Preto (SP): Escola de Enfermagem de Ribeirão Preto/USP; 1983. 9. Pitta A, organizadora. Reabilitação psicossocial no Brasil. São Paulo (SP): Hucitec; 1996.

10. Minzoni MA. Assistência de enfermagem psiquiátrica. [tese]. Ribeirão Preto (SP): Escola de Enfermagem de Ribeirão Preto/USP; 1971.

11. Dartigues A. O que é fenomenologia? Rio de Janeiro (RJ): Eldorado; 1973.

12. Martins J, Bicudo MAV. A pesquisa qualitativa em psicologia: fundamentos e recursos básicos. São Paulo (SP): Ed. Moraes; 1989.

13. Esposito VHC. Pesquisa qualitativa: modalidade fenomenológico-hermenêutica - relato de uma pesquisa. In: Bicudo MAV, Esposito VHC, organizadoras. A pesquisa qualitativa em educação: um enfoque fenomenológico. Piracicaba (SP): Ed.Unimep; 1994. p. 81-93.

14. Alencastre MB. Como o pessoal auxiliar de enfermagem vê o profissional enfermeiro: uma abordagem compreensiva. [tese]. Ribeirão Preto (SP): Escola de Enfermagem de Ribeirão Preto/USP; 1990.

15. Scatena MCM. O mundo do hospital psiquiátrico sob a perspectiva do doente que o habita. [tese]. Ribeirão Preto (SP): Escola de Enfermagem de Ribeirão Preto/USP; 1991. 16. Scheneider JF. A temporalidade do ser denominado esquizofrênico, fora de suas crises. [dissertação]. Ribeirão Preto (SP): Escola de Enfermagem de Ribeirão Preto/USP; 1995.

17. Resolução do Conselho Nacional de Saúde $n^{\circ} 196$ de 10 de outubro de 1996. Diretrizes e Normas reguladoras de pesquisas envolvendo seres humanos. [On line] [Acessado em 15/01/2000 ]. Disponível em URL: http://www.usf.br/cep/ res196.htm.

18. Rocha RM. Enfermagem psiquiátrica: que papel é este? Rio de Janeiro (RJ): Instituto Franco Basaglia: Ed. Te Corá; 1994.

19. Miranda CL. O parentesco imaginário: história e representação social da loucura nas relações do espaço asilar. São Paulo (SP): Cortez; 1994.

20. Silva EM. Supervisão do trabalho de enfermagem em saúde pública no nível local. [tese]. Ribeirão Preto (SP): Escola de Enfermagem de Ribeirão Preto/USP; 1997.

21. Patrício ZM. O processo de trabalho da enfermagem frente às novas concepções de saúde: repensando o cuidado/ propondo o cuidado (holístico). Texto Contexto Enfermagem 1993 jan/jun; 2(1):67-81.

22. Lopes MJM. Quando a voz e a palavra são atos terapêuticos: a integração individual e coletiva nas palavras quotidianas do trabalho de enfermagem. In: Waldow VR, Lopes MJM, Meyer DE. Maneiras de cuidar, maneiras de ensinar: a enfermagem entre a escola e a prática profissional. Porto Alegre (RS): Artes Médicas; 1995. p.153-88.

23. Heidegger $M$. Todos nós...ninguém: um enfoque fenomenológico do social. São Paulo (SP): Moraes; 1981.
24. Heidegger M. Ser e Tempo. 5. ed. Petrópolis (RJ): Vozes; 1995. Parte 1.

25. Lunardi VL. A sanção normalizadora e o exame: fios visíveis/invisíveis na docilização dos corpos das enfermeiras. In: Waldow VR, Lopes MJM, Meyer DE. Maneiras de cuidar, maneiras de ensinar: a enfermagem entre a escola e a prática profissional. Porto Alegre (RS): Artes Médicas; 1995. p.79108. 